\title{
EFFECT OF SUPPLEMENTATION OF WISTAR RATS WITH PROBIOTIC FERMENTED MILK ON THE GUT-BRAIN AXIS WITH EMPHASIS IN BEHAVIOR
}

\author{
Samara Máximo de Freitas, Milca Abda, Beatriz Franco, Luciana Carvalho Fino, Dra. Andrea Maculano Esteves, \\ Dra. Adriane Elisabete Antunes de Moraes.
}

\begin{abstract}
The gut microbiota is a complex ecosystem, associated with nutritional, metabolic, endocrine, immunological and psychological mechanisms; being the biocommunication between the intestine and brain stimulated by its products through the gut-brain axis. Supplementation with probiotics may provide host health benefits due to stimulation of growth of beneficial bacteria by modulating the microbiota. This project proposed to evaluate the effect of 30 day supplementation of Wistar rats with fermented milk containing probiotic ( 8 log CFU of B. animalis BB12). The drink was made and offered by gavage. The behavior parameters evaluated by Open Field were: total ambulation, rearing frequency, grooming frequency, total grooming duration and total freezing time.
\end{abstract}

Key words: Probiotics, Fermented Milk, Viability.

\section{Introduction}

The human gut microbiota is a set of commensal microorganisms that help maintain host health by participating in the development of the immune system and regulation of response to pathogens in addition to metabolic functions. The constituent genera of this microbiota may vary according to several factors, among them, the consumption of probiotics, which are defined by ANVISA (2018) ${ }^{1}$ as "living microorganisms that, when administered in adequate quantities, confer benefits to the health of the host". The influence of probiotics includes stimulating the proliferation of beneficial bacteria and the adverse action on the multiplication of harmful bacteria.

In addition, the microbiota acts in the Central Nervous System (CNS), through the Enteric Nervous System (NER), mediated by substances produced in the intestinal lumen, modulating the secretion of some neurotransmitters, involved with behavior, mood, memory and learning 2,3,4,5. Therefore, the objective of this study was to evaluate the behavior of Wistar rats supplemented with fermented milk containing probiotic.

\section{Results and Discussion}

The animals were divided into two groups: Control (CTRL) and Supplementary (SUPP), both of which received fermented milk by gavage - the CTRL group received the fermented placebo milk (containing only $S$. thermophilus) and the SUPP group received fermented milk with probiotic (B. animalis subs. lactis - BB12) for 30 days. During the intervention period, behavioral tests were performed using the Open Field test, which were carried out at the following moments: before the beginning of the supplementation (Basal) and at the 10th, 20th and 30th day of intervention (1M, $2 \mathrm{M}$ and $3 \mathrm{M}$, respectively).

As shown in Figure 1, the SUPP group presented a smaller decrease in some parameters in relation to the CTRL group, such as Total Ambulance, Rearing and Grooming, although without statistical significance. Regarding the Freezing parameter, the CTRL group presented a significant increase of the basal analysis and $1 \mathrm{M}$ for the analysis in $2 \mathrm{M}$ and $3 \mathrm{M}$. The Freezing time of the control group in $2 \mathrm{M}$ and $3 \mathrm{M}$ was significantly longer than the time of the SUPP group at all times. Regarding the Central Ambulation, it was noted that in both groups there was a decrease, but the SUPP group remained with the number of entries in the central quadrants of the larger arena at all times.

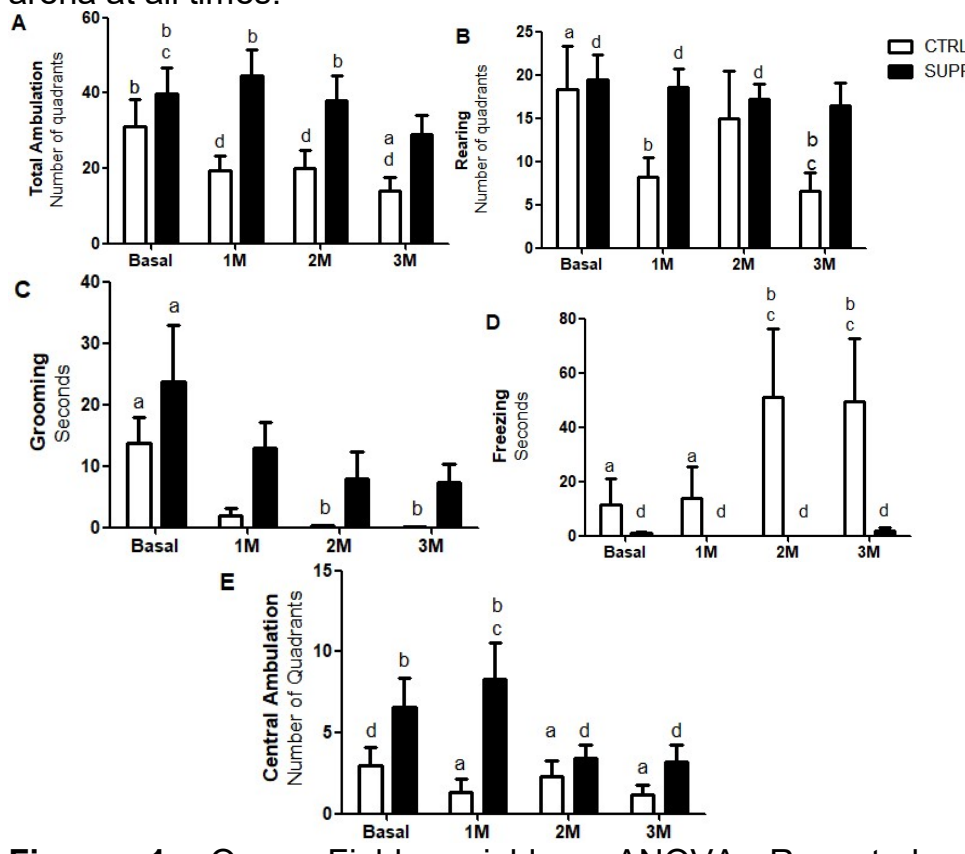

Figure 1. Open Field variables. ANOVA Repeated Measures. $p<0.05$. a differ $b, c$ differ $d$.

\section{Conclusions}

Considering what has been written in the literature, and the data obtained in the analyzes, it can be concluded that supplementation with probiotics had a protective effect in relation to changes related to anxiety behavior - such as increased Freezing and decrease Central Ambulance.

\section{Acknowledgement}

The authors thank PIBIC, CNPq and FAPESP (2018/05245$5)$.

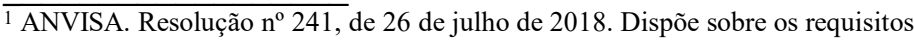
para comprovação.

2 FURTADO, C. C.; SILVA, A. L. B.; WALFALL, A. M. Psicobióticos: Uma Ferramenta para o Tratamento no Transtorno da Ansiedade e Depressão? Rev. Unilus Ens. e Pes., Santos, 15(40);137-151, 2018.

MAYER, E.A.; TILLISCH, K.; GUPTA, A. Gut/brain axis and the microbiota. Journal Of Clinical Investigation, [s.1.], 125(3); 926-938, 2015.

4 STÜRMER, E. S. et. al. A Importância dos Probióticos na Microbiota Intestinal Humana. Rev. Bras. de Nutrição Clínica, São Paulo, 27(4); 264-272, 2012

5 ZORZO, R. A. Impacto do Microbioma Intestinal no Eixo Cérebro-Intestino. International Journal of Nutrology, 1(10), 298-305, 2017.
} 